\title{
The pioneering of intracytoplasmic sperm injection: historical perspectives
}

\author{
Zev Rosenwaks and Nigel Pereira \\ Ronald O. Perelman and Claudia Cohen Center for Reproductive Medicine, Weill Cornell Medical College, \\ New York, New York, USA \\ Correspondence should be addressed to Z Rosenwaks; Email: zrosenw@med.cornell.edu
}

This paper is part of an Anniversary Issue celebrating 25 Years of intracytoplasmic sperm injection. The Guest Editor for this section was Professor Gianpiero Palermo.

\begin{abstract}
Intracytoplasmic sperm injection (ICSI) has often been heralded as a ground-breaking technique that has transformed the treatment of couples with infertility. By injecting a single spermatozoon into the cytoplasm of the oocyte, ICSI bypasses the zona pellucida and increases the chances of fertilization and subsequent embryo development, independent of semen parameters. Ever since the first live births using ICSI were reported in 1992, ICSI has become the mainstay of treating male factor infertility as well as overcoming fertilization failure associated with conventional in vitro insemination. Today, ICSI is utilized in nearly $66 \%$ of all assisted reproductive treatments worldwide and has resulted in the birth of millions of babies. The primary goal of this review is to provide historical perspectives about the pioneering of ICSI. We begin by highlighting the scientific work of early investigators who elucidated the mechanisms central to mammalian fertilization. Furthermore, we briefly discuss how these findings contributed to the development of IVF for the treatment of infertility. We then emphasize the shortcomings of IVF in treating severe forms of male factor infertility and enumerate the micromanipulation techniques that were developed to circumvent these shortcomings. Finally, we indicate how the inadequacies of these micromanipulation techniques lead to the inception, application and popularity of ICSI.

Reproduction (2017) 154 F71-F77
\end{abstract}

\section{Introduction}

The subject of infertility has stirred the interest of medical, social, religious and philosophical scholars from the beginning of human existence. Even though infertility was likened to a bad omen and was historically described using pseudoscientific and pagan terms, many civilizations documented its evidence at considerable length. For example, the ancient Egyptian Kahoun papyrus text, a medical textbook dating back to 1900 B.C., recognized several gynecologic conditions, including infertility (Morice et al. 1995). In fact, infertile women had their own goddess - Nephtys (Morice et al. 1995). Interestingly, not all cases of infertility were attributed to women, as evident from the story of Seth, lord of the desert, who was not able to conceive a child, even though his wife had a child with Osiris (Morice et al. 1995). The ancient Egyptians also proposed some simple methods of evaluating fertility in women, though much of it was permeated by magic and a limited knowledge of anatomy.

The Greeks, particularly Hippocrates and his pupils, wrote several treatises regarding infertility. Soranos of Ephesus, one of the greatest physicians of the Roman era, hypothesized that conception could occur only after the cessation of menstruation (Morice et al. 1995). While his reasoning was imperfect i.e. the uterus was overloaded at the time of menstruation, he was perhaps one of the first to suggest that conception could only occur during certain phases of the menstrual cycle. The basis of infertility was explored even more during the Middle Ages, the Renaissance and the early 20th century and was propelled by advances in anatomy and microscopy. However, most treatment methods were aimed at the surgical correction of reproductive tract anomalies.

In the 1890s, pivotal experiments were conducted by Walter Heape that would pave the way for human infertility treatment several decades later. Heape's embryo transfer experiments in rabbits were conducted between 1890 and 1897 and were subsequently published in the Proceedings of the Royal Society of London (Biggers 1991). In these experiments, Heape obtained two ova from the Angora doe rabbit, which had been fertilized approximately $32 \mathrm{~h}$ prior by an Angora buck. The ova were undergoing division into 4 segments. These ova were transferred into the fallopian tube of a Belgian hare doe rabbit, which had been fertilized by a buck of the same breed $3 \mathrm{~h}$ before. The Belgian hare doe rabbit then gave 
birth to 6 young ones -4 were similar to her and the buck's breed, while the remaining two were of the Angora breed. Heape's work, therefore, marked the first occurrence of deliberate embryo transfer and reimplantation in animals.

It is interesting to note that the implications of Heape's work for treating infertility were perhaps not recognized in the 1890s. However, two literarians furthered Heape's ideas in their books, and even alluded to the technique of modern-day in vitro fertilization (IVF). John Burdon Sanderson Haldane first introduced the concept of 'ectogenesis' in his 1925 book Daedalus, or, Science and the Future (Haldane 1925). In this book, Haldane envisioned a future where humans could create other human individuals outside their body. Soon after, in 1932, Aldous Huxley published Brave New World in which he proposed that 'bottled babies' could be created in the near future, though the development would be 'technically and ideologically still a long way' (Huxley 1932). An editorial appeared in the New England Journal of Medicine on October 21st 1937 apprising the medical community about the scientific and ethical implications of Huxley's ideas (Editorial 1937). However, before any of these ideas could be realized or dismissed, it became imperative to address whether oocytes could undergo fertilization and normal development in in vitro conditions.

\section{Achieving fertilization in in vitro conditions}

Early studies of fertilization were conducted in invertebrate animals such as the sea urchin and starfish (Yanagimachi 2012). These animals generally produced millions of mature oocytes at one time, with fertilization and subsequent embryo development occurring outside the body (Yanagimachi 2012). Furthermore, the early stages of development could be observed in a simple dish of sea water under laboratory conditions (Yanagimachi 2012). Although 40-50 mammalian oocytes could be obtained from mice or rabbits using superovulation, the process of fertilization occurred inside the body of a female (Yanagimachi 2012). This limited the number of in vitro observations and experiments that could be conducted in laboratory conditions using mammalian oocytes. However, the work of Pincus and Enzmann served as a major break-through (Pincus \& Enzmann 1934). In their 1934 paper, the authors demonstrated normal development of mammalian oocytes that were subjected to in vitro experimental manipulation (Pincus \& Enzmann 1934). In one of their experiments, an albino doe was made pseudopregnant via copulation with a vasectomized male. Ova were then obtained at the 1-cell stage from the fallopian tubes of an English doe that was mated with a fertile agouti male. These ova were cultured in Carrel flasks for $20 \mathrm{~h}$, after which 5 ova were transplanted into the left fallopian tube of the pseudopregnant albino doe. Thirty days later, 2 gray English-spotted young were obtained.
Fertilizing oocytes with male gametes in in vitro conditions was the next logical step to follow Pincus' and Enzmann's work. Two successive papers published by Rock and Menkin in 1944 and 1948 described the early stages of oocyte fertilization in humans (Rock \& Menkin 1944, 1948). In one study, 800 oocytes were retrieved from women undergoing various gynecologic surgeries, of which, 138 were exposed to spermatozoa (Rock \& Menkin 1948). Two oocytes were found to be in the 2-cell stage, while two others were in the 3-cell stage after culturing with human blood serum. Although poor fertilization of oocytes was an acknowledged limitation of the aforementioned studies, the reasons for poor fertilization remained unknown. However, in a series of papers published in Nature, M C Chang described the vital process of sperm capacitation, which was imperative for successful in vivo fertilization (Chang 1951, 1953, 1955). A few years later, in 1959, Chang also provided the irrefutable evidence forlVF of gametes (Chang 1959). In his study, Chang collected mature unfertilized oocytes from albino female rabbits injected with sheep pituitary extract. Spermatozoa were collected from the uteri of albino females that were mated with albino males $12 \mathrm{~h}$ prior. The oocytes were inseminated with spermatozoa in a Carrel flask on a rocker. Approximately $4 \mathrm{~h}$ later, the oocytes were transferred to another flask containing $50 \%$ heated serum in saline and cultured until the 4-cell stage. Thirtysix cleaving oocytes were transferred into 6 black female rabbits; four rabbits delivered 15 young albinos. Chang's IVF experiments, in conjunction with improved oocyte collection techniques, microscopes, culture dishes and media, served as the harbinger of IVF attempts in humans (Edwards et al. 1966, De Kretzer et al. 1973, Steptoe \& Edwards 1976), culminating in the birth of Louise Brown, the first IVF baby in 1978 (Steptoe \& Edwards 1978).

\section{Success and limitations of IVF}

Although Edwards and Steptoe reported the first IVF birth in a woman with bilateral tubal occlusions (Steptoe \& Edwards 1978), many investigators envisaged the application of IVF for other infertility diagnoses as well. By inducing the growth of multiple follicles with clomiphene citrate (Trounson et al. 1981), IVF was no longer limited to a single oocyte retrieved during the natural menstrual cycle as described originally (Steptoe \& Edwards 1978). Several good-quality embryos could be generated after fertilization of the retrieved oocytes, following which two or more embryos could be transferred (Edwards et al. 1984, Muasher et al. 1984). Such a strategy boosted the success and efficacy of IVF by several-fold. Studies from Monash University in Australia indicated that pregnancy rates had increased from $4-13 \%$ to $18-22 \%$ before and after using clomiphene citrate, respectively (Trounson \& Wood 1981, 1984, Trounson 1982). Similar protocols were used at the Bourn Hall clinic in England, resulting in increased 
implantation rates i.e., 16.5-30\% (Edwards et al. 1984). At Norfolk, USA, comparable protocols resulted in 105 pregnancies (319 patients) between 1981 and 1983, with pregnancy rates of $19 \%$ and $25 \%$ per cycle and per transfer, respectively (Jones et al. 1984).

Despite its early success, several clinics began to note significant limitations of IVF. In fact, about $40 \%$ of IVF cycles were complicated by poor fertilization or complete fertilization failure (CFF), even when an adequate number of oocytes were retrieved (Cohen et al. 1984, Mahadevan \& Trounson 1984). The aforementioned fertilization issues were especially pronounced in couples where the male partner had moderate-tosevere abnormalities in semen parameters. Laboratories attempted to reduce the incidence of poor fertilization and CFF by increasing in vitro sperm concentrations (Palermo et al. 2014a,b). For example, when ejaculated specimens with sub-optimal semen parameters were obtained, the volume of the insemination medium was decreased, so as to increase the overall concentration of sperm. This facilitated the in vitro co-mingling of gametes (Palermo et al. 2014a,b). Multilayer density gradients or swim-up techniques were also utilized to increase the fraction of motile and morphologically normal sperm available for in vitro insemination (Alper et al. 1985). Sperm motility enhancers such as pentoxifylline were shown to increase fertilization rates in some couples undergoing IVF for severe male factor infertility (Yovich et al. 1990). Although the aforementioned methods increased the fertilization and pregnancy rates of IVF cycles for mild-to-moderate asthenozoospermia or oligozoospermia, their success remained limited in IVF cycles for severe oligo-asthenozoospermia or complete teratozoospermia.

\section{Assisted fertilization}

Given the incidence of poor fertilization and CFF in IVF cycles with sub-optimal sperm concentration and motility, investigators began to develop assays that could predict the fertilization potential of spermatozoa. The hemizona assay (HZA) was one such example where maximal binding of sperm samples to matching halves of a human zona pellucida (ZP) from a nonfertilizable and nonliving oocyte was evaluated after 4-5 h of coincubation (Burkman et al. 1988). Studies demonstrated that tight zona binding was significantly correlated with the percentage of motile sperm and normal morphology, as well as sperm concentration (Franken et al. 1989). Further studies also confirmed that patients with poor fertilization rates in IVF had significantly lower binding than patients with successful fertilization, with a sensitivity, specificity and positive predictive value of 83,95 and $83 \%$, respectively for fertilization (Oehninger et al. 1989). However, due to the limited availability of zonae, the HZA was limited to only a few specialized laboratories.
Although the HZA served as a valuable tool to evaluate sperm-ZP binding, it offered no therapeutic benefits i.e., it did not increase the fertilizing potential of poor-quality spermatozoa. Thus, the focus switched to assisted fertilization, which aimed at increasing the fertilizing potential of sperm by bypassing the cumulus cells and the thick glycoprotein coat (ZP) surrounding the oocyte. Early investigations aimed at complete removal of the cumulus cells to aid fertilization. In one such study (Lavy et al. 1988), 88 oocytes from 13 patients with male factor, immunological and idiopathic infertility were randomly assigned to cumulus removal with hyaluronidase or nontreatment. While cumulus removal did increase fertilization rates in some cases, only 1 clinical pregnancy was achieved.

Different investigators then attempted to remove the ZP completely; however, such attempts invariably resulted in polyspermy and abnormal embryo development. Milder variants of zona removal were also used - for example, mild trypsinization of oocytes prior to in vitro insemination (Kiessling et al. 1988). Yet, polyspermy was still noted in 1 out of 3 treated patients. Localized chemical treatment of oocytes with acidified Tyrode's solution prior to sperm exposure, also known as zona drilling, was another method of introducing deliberate gaps in the ZP to facilitate sperm entry (Gordon \& Talansky 1986). However, its application was limited by the $50 \%$ rate of polyspermy in drilled oocytes (Gordon et al. 1988). In addition, zona drilling involved exposure to a solution of $\mathrm{pH} 2.3$, thereby increasing the risk of chemical damage to oocytes (Gordon et al. 1988). Zona drilling was refined further by creating a partial opening in the ZP with mechanical force. This technique was called partial zona dissection (PZD) and was considered less traumatic than zona drilling (Cohen et al. 1988, Malter \& Cohen 1989). Also, to avoid ooplasmic damage, the oocytes were exposed to sucrose to shrink the ooplasm during micromanipulation (Cohen et al. 1988, Malter \& Cohen 1989). In one study, 11 male factor infertility couples had some of their oocytes treated with PZD prior to in vitro insemination, while the remaining non-PZDtreated oocytes served as controls (Cohen et al. 1989). The investigators reported that the rates of monospermic fertilization and cleavage $(23 / 34 ; 68 \%)$ with PZD were almost double when compared to the control oocytes (10/30; 33\%) (Cohen et al. 1989). Furthermore, three PZD embryos also progressed to the blastocyst stage. Despite these encouraging results, investigators noted that polyspermy continued to occur with PZD (Cohen et al. 1988, Malter \& Cohen 1989).

The limitations of PZD gave rise to another micromanipulation technique called subzonal insemination (SUZI) (Ng et al. 1988). In this technique (Fig. 1, Panel A), up to 3 spermatozoa were brought with an injection pipette through the ZP and deposited into the perivitelline space of a metaphase-II oocyte 


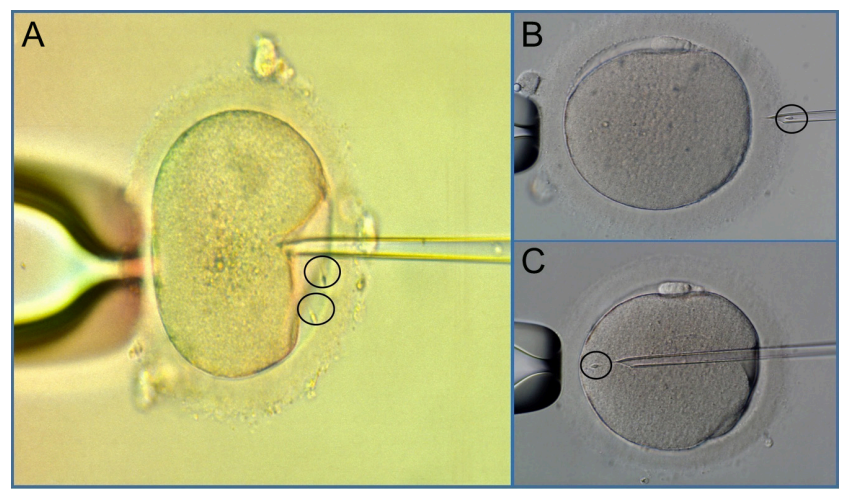

Figure 1 Panel A - subzonal insemination (SUZI) of oocytes in which 2-3 spermatozoa (black circles) are brought with an injection pipette through the zona pellucida and deposited into the perivitelline space; Panel B - a single spermatozoon (black circle) is seen in the injection pipette prior to performing sperm injection; Panel $\mathrm{C}$ - a single spermatozoon (black circle) is seen in cytoplasm of the oocyte immediately after sperm injection.

(Ng et al. 1988, Palermo \& Van Steirteghem 1991). The initial results of SUZI were encouraging. For example, when SUZI was performed in 771 oocytes from 131 patients with very low sperm density and motility, the rates of monospermic fertilization and polyspermy were $16.6 \%$ and $2.3 \%$, respectively ( $\mathrm{Ng}$ et al. 1991). In another study of 43 couples with a history of CFF with IVF, subzonal insemination of 433 metaphase-II oocytes achieved a fertilization rate of $30.9 \%$ and subsequent cleavage rate of $80 \%$ (Palermo et al. 1992a). The overall pregnancy rate with SUZI, however, remained relatively low, ranging from $2.9 \%$ to $16.3 \%$ (Palermo et al. 1992a, Sakkas et al. 1992). Given the collective limitations of zona drilling, PZD and SUZI, systematic efforts were undertaken to develop a micromanipulation method that would optimize the fertilizing potential of a single spermatozoon and increase pregnancy rates, but also decrease the incidence of polyspermy and poor fertilization.

\section{Inception of ICSI}

Fertilization of an oocyte by injecting a single spermatozoon into the ooplasm was previously achieved in sea urchin (Hiramoto 1962a,b), mouse (Lin 1966) and hamster models (Uehara \& Yanagimachi $1977 a, b)$. However, replication of this technique in other mammalian models was often complicated by oocyte damage and lysis, with only $30 \%$ of oocytes surviving the injection procedure (Thadani 1980, Markert 1983). Much of the oocyte damage was attributed to the crudeness of the micromanipulation instruments (Pereira et al. 2016). Furthermore, because sperm injection bypassed ZP-sperm fusion, oocyte activation was required in most species, which was generally achieved by vigorous suction of ooplasm just before sperm injection (Perreault \& Zirkin 1982) or with compounds such as A23187 (Palermo \& Van Steirteghem 1991).

The first offspring using sperm injection into oocytes were achieved in rabbits (Iritani et al. 1988) followed by bovine species (Goto et al. 1990). Microinjection of a spermatozoon directly into the ooplasm of human oocytes was attempted in 11 patients as early as 1987. While this was the first description of successful fertilization of human oocytes with sperm microinjection, no zygotes were transferred in this study (Lanzendorf et al. 1988). Evidence mounted that injection of a single spermatozoon into a human oocyte would require intricate micromanipulation tools and holding dishes, as well as a standardized technique. Extensive work was carried out to improve the preexisting micromanipulators i.e. refining of the injection needles, newer holding and injecting pipettes, delivery of a constant pressure through a $5 \mu$ diameter microneedle, as well as standardization of intracytoplasmic sperm injection (ICSI) dishes. It was while performing SUZI, with the aforementioned modifications, that the oolemma and ooplasm of an oocyte was inadvertently pierced with a single spermatozoon. The oocyte was re-examined the following day; two pronuclei were noted, which confirmed fertilization (Palermo et al. 1992b). This was perhaps the inception of ICSI (Fig. 1, Panels B and C). Figure 2 provides a simplified timeline of micromanipulation techniques leading up to the pioneering of ICSI.

\section{Application and popularity of ICSI}

The first four pregnancies using ICSI were reported in couples with severely impaired sperm characteristics and failed IVF and SUZI attempts (Palermo et al. 1992b). Initial comparisons of ICSI and SUZI demonstrated fertilization rates of $44 \%$ and $18 \%$, respectively (Palermo et al. 1993). However, further research demonstrated that the fertilization rates with ICSI could be increased with aggressive sperm immobilization i.e., crimping the sperm flagellum between the midpiece and the rest of the tail prior to sperm injection (Palermo et al. 1996). For example, in a study of 837 cycles, ICSI after aggressive sperm immobilization was associated with fertilization and pregnancy rates of $82 \%$ and $82.4 \%$, respectively compared to fertilization and pregnancy rates of $48.3 \%$ and $51.4 \%$, respectively with standard sperm immobilization and ICSI (Palermo et al. 1996). Early adopters of ICSI were also able to improve fertilization and pregnancy rates by following specialized technical steps and adhering to stringent laboratory conditions while performing ICSI (Palermo et al. 2015). Similar to PZD and SUZI, ICSI allowed precise identification of fertilization by the appearance of the pronuclei and the first embryonic cleavage (Palermo et al. 2009, 2015). ICSI was also able to shed light on the genetics of abnormal human fertilization as well as the involvement of the 


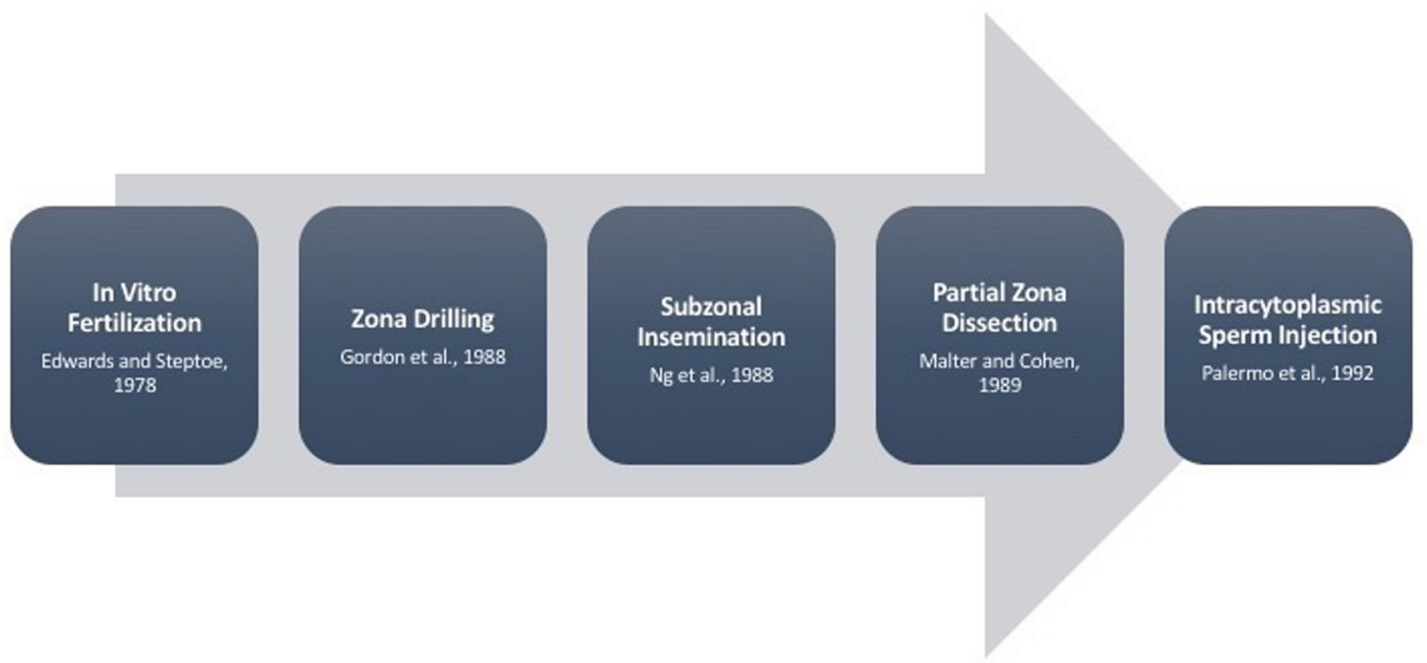

Figure $2 \mathrm{~A}$ simplified timeline of micromanipulation techniques leading up to the pioneering of intracytoplasmic sperm injection (ICSI).

human sperm centrosome in controlling the first mitotic division after fertilization (Palermo et al. 1994, 1995a).

With the accumulation of more scientific evidence, it became apparent that ICSI was capable of fertilizing nearly every mature oocyte injected, irrespective of sperm source (Palermo et al. 1995b, 1998, Schlegel et al. 1995a,b, Su et al. 1999) and spermatozoa characteristics (Alikani et al. 1995, Chung et al. 1998, Palermo et al. 1999, Chan et al. 2001). In their recent publication, the International Committee for Monitoring Assisted Reproductive Technologies (ICMART) reported that ICSI was utilized in $66 \%$ of $>4,461,309$ cycles in 61 countries between 2008 and 2010 (Dyer et al. 2016). Interestingly, geographic variations in ICSI utilization were also reported by ICMART - 55\% in Asia, 65\% in Europe and $100 \%$ in the Middle East. As quoted in the ICMART report, 'the reasons behind the high use of ICSI in some regions are not fully understood and are outside of the scope of this report' (Dyer et al. 2016). In the USA, the use of ICSI has increased from 36.4\% in 1996 to $76.2 \%$ in 2012 (Boulet et al. 2015). Of note, ICSI is being increasingly utilized even in the presence of normal semen parameters (Jain \& Gupta et al. 2007). For example, the use of ICSI in the USA for non-male factor infertility increased from $15.4 \%$ in 1996 to $66.9 \%$ in 2012 (Boulet et al. 2015). The increased utilization of ICSI in the USA may correspond to the increase in preimplantation genetic testing, use of cryopreserved oocytes or in vitro maturation (Practice Committees of the American Society for Reproductive Medicine and Society for Assisted Reproductive Technology 2012, Boulet et al. 2015). However, it is still imperative to analyze the trend of increasing ICSI utilization in nonmale factor settings, without any apparent benefits. In one recent study, the reproductive outcomes of 490 and 255 women $>40$ years of age undergoing ICSI and conventional IVF, respectively were compared
(Tannus et al. 2017). Despite similar numbers of total oocytes retrieved, the conventional IVF group had more mature oocytes. The conventional IVF group also had a statistically higher number of zygotes. The fertilization rates, fertilization failure rates and live birth rates were similar between the ICSI and conventional IVF groups. In another study, the reproductive outcomes of couples with a history of tubal ligation and no male factor were compared by method of insemination i.e. ICSI vs conventional IVF (Grimstad et al. 2016). The authors compared 3189 ICSI cycles to 3956 IVF cycles and found no significant improvement in the fertilization rate. Furthermore, the odds of clinical pregnancy and live birth were lower in the ICSI group. While these and other previously published studies pertaining to the use of ICSI in non-male factor settings have led the American Society for Reproductive Medicine and the Society for Assisted Reproductive Technology to confirm that there is insufficient evidence to support the routine use of ICSI in patients without male factor infertility (Practice Committees of the American Society for Reproductive Medicine and Society for Assisted Reproductive Technology 2012), it is important to highlight that the use of ICSI should be individualized to the reproductive history of the couple (Palermo et al. 2015).

\section{Declaration of interest}

The authors declare that there is no conflict of interest that could be perceived as prejudicing the impartiality of this review.

\section{Funding}

This research did not receive any specific grant from any funding agency in the public, commercial or not-for-profit sector. 


\section{References}

Alikani M, Palermo G, Adler A, Bertoli M, Blake M \& Cohen J 1995 Intracytoplasmic sperm injection in dysmorphic human oocytes. Zygote 3 283-288. (https://doi.org/10.1017/S0967199400002707)

Alper MM, Lee GS, Seibel MM, Smith D, Oskowitz SP, Ransil BJ \& Taymor ML 1985 The relationship of semen parameters to fertilization in patients participating in a program of in vitro fertilization. Journal of in Vitro Fertilization and Embryo Transfer 2 217-223. (https://doi. org/10.1007/BF01201800)

Biggers JD 1991 Walter Heape, FRS: a pioneer in reproductive biology. Centenary of his embryo transfer experiments. Journal of Reproduction and Fertility 93 173-186. (https://doi.org/10.1530/jrf.0.0930173)

Boulet SL, Mehta A, Kissin DM, Warner L, Kawwass JF \& Jamieson DJ 2015 Trends in use of and reproductive outcomes associated with intracytoplasmic sperm injection. JAMA 313 255-263. (https://doi. org/10.1001/jama.2014.17985)

Burkman LJ, Coddington CC, Franken DR, Krugen TF, Rosenwaks Z \& Hogen GD 1988 The hemizona assay (HZA): development of a diagnostic test for the binding of human spermatozoa to the human hemizona pellucida to predict fertilization potential. Fertility and Sterility 49 688-697. (https://doi.org/10.1016/S0015-0282(16)59841-0)

Chan PT, Palermo GD, Veeck LL, Rosenwaks Z \& Schlegel PN 2001 Testicular sperm extraction combined with intracytoplasmic sperm injection in the treatment of men with persistent azoospermia postchemotherapy. Cancer $92 \quad 1632-1637 . \quad$ (https://doi.org/10.1002/10970142(20010915)92:6<1632::AID-CNCR1489>3.0.CO;2-I)

Chang MC 1951 Fertilizing capacity of spermatozoa deposited into the fallopian tubes. Nature 168697-698. (https://doi.org/10.1038/168697b0)

Chang MC 1953 Storage of unfertilized rabbit ova; subsequent fertilization and the probability of normal development. Nature 172 353-354. (https://doi.org/10.1038/172353b0)

Chang MC 1955 Development of fertilizing capacity of rabbit spermatozoa in the uterus. Nature 175 1036-1037. (https://doi.org/10.1038/1751036a0)

Chang MC 1959 Fertilization of rabbit ova in vitro. Nature 184 466-467. (https://doi.org/10.1038/184466a0)

Chung PH, Palermo G, Schlegel PN, Veeck LL, Eid JF \& Rosenwaks Z 1998 The use of intracytoplasmic sperm injection with electroejaculates from anejaculatory men. Human Reproduction 13 1854-1858. (https://doi. org/10.1093/humrep/13.7.1854)

Cohen J, Edwards RG, Fehilly CB, Fishel SB, Hewitt J, Rowland G, Steptoe PC \& Webster J 1984 Treatment of male infertility by in vitro fertilization: factors affecting fertilization and pregnancy. Acta Europaea Fertilitatis 15 455-465.

Cohen J, Malter H, Fehilly C, Wright G, Elsner C, Kort H \& Massey J 1988 Implantation of embryos after partial opening of oocyte zona pellucida to facilitate sperm penetration. Lancet 2 162. (https://doi.org/10.1016/ S0140-6736(88)90710-6)

Cohen J, Malter H, Wright G, Kort H, Massey J \& Mitchell D 1989 Partial zona dissection of human oocytes when failure of zona pellucida penetration is anticipated. Human Reproduction 4 435-442. (https://doi. org/10.1093/oxfordjournals.humrep.a136923)

De Kretzer D, Dennis P, Hudson B, Leeton J, Lopata A, Outch K, Talbot J \& Wood C 1973 Transfer of a human zygote. Lancet 2 728-729.

Dyer S, Chambers GM, de Mouzon J, Nygren KG, Zegers-Hochschild F, Mansour R, Ishihara O, Banker M \& Adamson GD 2016 International Committee for Monitoring Assisted Reproductive Technologies world report: assisted reproductive technology 2008, 2009 and 2010. Human Reproduction 31 1588-1609. (https://doi.org/10.1093/humrep/dew082)

Editorial 1937 Conception in a watch glass. New England Journal of Medicine 217678.

Edwards RG, Donahue RP, Baramki TA \& Jones HW Jr 1966 Preliminary attempts to fertilize human oocytes matured in vitro. American Journal of Obstetrics and Gynecology 96 192-200. (https://doi.org/10.1016/00029378(66)90315-2)

Edwards RG, Fishel SB, Cohen J, Fehilly CB, Purdy JM, Slater JM, Steptoe PC \& Webster JM 1984 Factors influencing the success of in vitro fertilization for alleviating human infertility. Journal of in Vitro Fertilization and Embryo Transfer 1 3-23. (https://doi.org/10.1007/ BF01129615)

Franken DR, Oehninger S, Burkman LJ, Coddington CC, Kruger TF, Rosenwaks Z, Acosta AA \& Hodgen GD 1989 The hemizona assay $(\mathrm{HZA})$ : a predictor of human sperm fertilizing potential in in vitro fertilization (IVF) treatment. Journal of in Vitro Fertilization and Embryo Transfer 6 44-50. (https://doi.org/10.1007/BF01134581)

Gordon JW \& Talansky BE 1986 Assisted fertilization by zona drilling: a mouse model for correction of oligospermia. Journal of Experimental Zoology 239 347-354. (https://doi.org/10.1002/jez.1402390306)

Gordon JW, Grunfeld L, Garrisi GJ, Talansky BE, Richards C \& Laufer N 1988 Fertilization of human oocytes by sperm from infertile males after zona pellucida drilling. Fertility and Sterility 50 68-73. (https://doi. org/10.1016/S0015-0282(16)60010-9)

Goto K, Kinoshita A, Takuma Y \& Ogawa K 1990 Fertilisation of bovine oocytes by the injection of immobilised, killed spermatozoa. Veterinary Record 127 517-520.

Grimstad FW, Nangia AK, Luke B, Stern JE \& Mak W 2016 Use of ICSI in IVF cycles in women with tubal ligation does not improve pregnancy or live birth rates. Human Reproduction 31 2750-2755. (https://doi. org/10.1093/humrep/dew247)

Haldane JBS 1925 Daedalus; or, Science and the Future; A Paper Read to the Heretics, Cambridge, on February 4th, 1923. London: K. Paul, Trench, Trubner \& Co.

Hiramoto Y 1962a An analysis of the mechanism of fertilation by means of enucleation of sea urchin eggs. Experimental Cell Research 28 323-334. (https://doi.org/10.1016/0014-4827(62)90286-0)

Hiramoto Y 1962b Microinjection of the live spermatozoa into sea urchin eggs. Experimental Cell Research 27 416-426. (https://doi. org/10.1016/0014-4827(62)90006-X)

Huxley A 1932 Brave New World, A Novel. Garden City, NY: Doubleday, Doran \& Co.

Iritani A, Utsumi K, Miyake M, Hosoi Y \& Saeki K 1988 In vitro fertilization by a routine method and by micromanipulation. Annals of the New York Academy of Sciences 541 583-590. (https://doi. org/10.1111/j.1749-6632.1988.tb22295.x)

Jain T \& Gupta RS 2007 Trends in the use of intracytoplasmic sperm injection in the United States. New England Journal of Medicine 357 251-257. (https://doi.org/10.1056/NEJMsa070707)

Jones HW Jr, Acosta AA, Andrews MC, Garcia JE, Jones GS, Mayer J, McDowell JS, Rosenwaks Z, Sandow BA, Veeck LL et al. 1984 Three years of in vitro fertilization at Norfolk. Fertility and Sterility 42 826-834. (https://doi.org/10.1016/S0015-0282(16)48251-8)

Kiessling AA, Loutradis D, McShane PM \& Jackson KV 1988 Fertilization in trypsin-treated oocytes. Annals of the New York Academy of Sciences 541 614-620. (https://doi.org/10.1111/j.1749-6632.1988.tb22298.x)

Lanzendorf SE, Maloney MK, Veeck LL, Slusser J, Hodgen GD \& Rosenwaks Z 1988 A preclinical evaluation of pronuclear formation by microinjection of human spermatozoa into human oocytes. Fertility and Sterility 49 835-842. (https://doi.org/10.1016/S0015-0282(16)59893-8)

Lavy G, Boyers SP \& DeCherney AH 1988 Hyaluronidase removal of the cumulus oophorus increases in vitro fertilization. Journal of in Vitro Fertilization and Embryo Transfer 5 257-260. (https://doi.org/10.1007/ BF01132173)

Lin TP 1966 Microinjection of mouse eggs. Science 151 333-337. (https:// doi.org/10.1126/science.151.3708.333)

Mahadevan MM \& Trounson AO 1984 The influence of seminal characteristics on the success rate of human in vitro fertilization. Fertility and Sterility 42 400-405. (https://doi.org/10.1016/S00150282(16)48080-5)

Malter HE \& Cohen J 1989 Partial zona dissection of the human oocyte: a nontraumatic method using micromanipulation to assist zona pellucida penetration. Fertility and Sterility 51 139-148. (https://doi.org/10.1016/ S0015-0282(16)60443-0)

Markert CL 1983 Fertilization of mammalian eggs by sperm injection. Journal of Experimental Zoology 228 195-201. (https://doi.org/10.1002/ jez.1402280205)

Menkin MF \& Rock J 1948 In vitro fertilization and cleavage of human ovarian eggs. American Journal of Obstetrics and Gynecology $\mathbf{5 5}$ 440-452. (https://doi.org/10.1016/S0002-9378(15)32963-X)

Morice P, Josset P, Chapron C \& Dubuisson JB 1995 History of infertility. Human Reproduction Update 1 497-504. (https://doi.org/10.1093/ humupd/1.5.497)

Muasher SJ, Wilkes C, Garcia JE, Rosenwaks Z \& Jones HW Jr 1984 Benefits and risks of multiple transfer with in vitro fertilisation. Lancet 1 570. (https://doi.org/10.1016/S0140-6736(84)90974-7)

Ng SC, Bongso A, Ratnam SS, Sathananthan H, Chan CL, Wong PC, Hagglund L, Anandakumar C, Wong YC \& Goh VH 1988 Pregnancy after 
transfer of sperm under zona. Lancet 2 790. (https://doi.org/10.1016/ S0140-6736(88)92433-6)

Ng SC, Bongso A \& Ratnam SS 1991 Microinjection of human oocytes: a technique for severe oligoasthenoteratozoospermia. Fertility and Sterility 56 1117-1123. (https://doi.org/10.1016/S0015-0282(16)54726-8)

Oehninger S, Coddington CC, Scott R, Franken DA, Burkman LJ, Acosta AA \& Hodgen GD 1989 Hemizona assay: assessment of sperm dysfunction and prediction of in vitro fertilization outcome. Fertility and Sterility $\mathbf{5 1}$ 665-670. (https://doi.org/10.1016/S0015-0282(16)60618-0)

Palermo G \& Van Steirteghem A 1991 Enhancement of acrosome reaction and subzonal insemination of a single spermatozoon in mouse eggs. Molecular Reproduction and Development 30 339-345. (https://doi. org/10.1002/mrd.1080300408)

Palermo G, Joris H, Devroey P \& Van Steirteghem AC 1992a Induction of acrosome reaction in human spermatozoa used for subzonal insemination. Human Reproduction 7 248-254. (https://doi. org/10.1093/oxfordjournals.humrep.a137626)

Palermo G, Joris H, Devroey P \& Van Steirteghem AC 1992b Pregnancies after intracytoplasmic injection of single spermatozoon into an oocyte. Lancet 340 17-18. (https://doi.org/10.1016/0140-6736(92)92425-F)

Palermo G, Joris H, Derde MP, Camus M, Devroey P \& Van Steirteghem A 1993 Sperm characteristics and outcome of human assisted fertilization by subzonal insemination and intracytoplasmic sperm injection. Fertility and Sterility 59 826-835. (https://doi.org/10.1016/S00150282(16)55867-1)

Palermo G, Munné S \& Cohen J 1994 The human zygote inherits its mitotic potential from the male gamete. Human Reproduction 9 1220-1225. (https://doi.org/10.1093/oxfordjournals.humrep.a138682)

Palermo GD, Cohen J, Alikani M, Adler A \& Rosenwaks Z 1995a Intracytoplasmic sperm injection: a novel treatment for all forms of male factor infertility. Fertility and Sterility 63 1231-1240. (https://doi. org/10.1016/S0015-0282(16)57603-1)

Palermo GD, Munné S, Colombero LT, Cohen J \& Rosenwaks Z 1995b Genetics of abnormal human fertilization. Human Reproduction 10 120-127. (https://doi.org/10.1093/humrep/10.suppl_1.120)

Palermo GD, Schlegel PN, Colombero LT, Zaninovic N, Moy F \& Rosenwaks Z 1996 Aggressive sperm immobilization prior to intracytoplasmic sperm injection with immature spermatozoa improves fertilization and pregnancy rates. Human Reproduction 11 1023-1029. (https://doi.org/10.1093/oxfordjournals.humrep.a019290)

Palermo GD, Schlegel PN, Sills ES, Veeck LL, Zaninovic N, Menendez S \& Rosenwaks Z 1998 Births after intracytoplasmic injection of sperm obtained by testicular extraction from men with nonmosaic Klinefelter's syndrome. New England Journal of Medicine 338 588-590. (https://doi. org/10.1056/NEJM199802263380905)

Palermo GD, Schlegel PN, Hariprashad JJ, Ergün B, Mielnik A, Zaninovic N, Veeck LL \& Rosenwaks Z 1999 Fertilization and pregnancy outcome with intracytoplasmic sperm injection for azoospermic men. Human Reproduction 14 741-748. (https://doi.org/10.1093/humrep/14.3.741)

Palermo GD, Neri QV, Takeuchi T \& Rosenwaks Z 2009 ICSI: where we have been and where we are going. Seminars in Reproductive Medicine 27 191-201. (https://doi.org/10.1055/s-0029-1202309)

Palermo GD, Kocent J, Monahan D, Neri QV \& Rosenwaks Z 2014a Treatment of male infertility. Methods in Molecular Biology 1154 385-405.

Palermo GD, Neri QV, Schlegel PN \& Rosenwaks Z 2014b Intracytoplasmic sperm injection (ICSI) in extreme cases of male infertility. PLOS ONE 9 e113671. (https://doi.org/10.1371/journal.pone.0113671)

Palermo GD, Neri QV \& Rosenwaks Z 2015 To ICSI or not to ICSI. Seminars in Reproductive Medicine 33 92-102. (https://doi. org/10.1055/s-0035-1546825)

Pereira N, Cozzubbo T, Cheung S \& Palermo GD 2016 Lessons learned in andrology: from intracytoplasmic sperm injection and beyond. Andrology 4 757-760. (https://doi.org/10.1111/andr.12225)

Perreault SD \& Zirkin BR 1982 Sperm nuclear decondensation in mammals: role of sperm-associated proteinase in vivo. Journal of Experimental Zoology 224 253-257. (https://doi.org/10.1002/jez.1402240215)

Pincus G \& Enzmann EV 1934 Can mammalian eggs undergo normal development in vitro? PNAS 20 121-122. (https://doi.org/10.1073/ pnas.20.2.121)
Practice Committees of the American Society for Reproductive Medicine and Society for Assisted Reproductive Technology 2012 Intracytoplasmic sperm injection (ICSI) for non-male factor infertility: a committee opinion. Fertility and Sterility 98 1395-1399.

Rock J \& Menkin MF 1944 In vitro fertilization and cleavage of human ovarian eggs. Science 100 105-107. (https://doi.org/10.1126/ science.100.2588.105)

Sakkas D, Lacham O, Gianaroli L \& Trounson A 1992 Subzonal sperm microinjection in cases of severe male factor infertility and repeated in vitro fertilization failure. Fertility and Sterility 57 1279-1288. (https://doi. org/10.1016/S0015-0282(16)55088-2)

Schlegel PN, Cohen J, Goldstein M, Alikani M, Adler A, Gilbert BR, Palermo GD \& Rosenwaks Z 1995a Cystic fibrosis gene mutations do not affect sperm function during in vitro fertilization with micromanipulation for men with bilateral congenital absence of vas deferens. Fertility and Sterility 64 421-426. (https://doi.org/10.1016/S0015-0282(16)57745-0)

Schlegel PN, Palermo GD, Alikani M, Adler A, Reing AM, Cohen J \& Rosenwaks Z 1995b Micropuncture retrieval of epididymal sperm with in vitro fertilization: importance of in vitro micromanipulation techniques. Urology 46 238-241. (https://doi.org/10.1016/S0090-4295(99)80199-X)

Steptoe PC \& Edwards RG 1976 Reimplantation of a human embryo with subsequent tubal pregnancy. Lancet 1 880-882. (https://doi.org/10.1016/ S0140-6736(76)92096-1)

Steptoe PC \& Edwards RG 1978 Birth after the reimplantation of a human embryo. Lancet 2 366. (https://doi.org/10.1016/S0140-6736(78)92957-4)

Su LM, Palermo GD, Goldstein M, Veeck LL, Rosenwaks Z \& Schlegel PN 1999 Testicular sperm extraction with intracytoplasmic sperm injection for nonobstructive azoospermia: testicular histology can predict success of sperm retrieval. Journal of Urology 161 112-116. (https://doi. org/10.1016/S0022-5347(01)62079-2)

Tannus S, Son WY, Gilman A, Younes G, Shavit T \& Dahan MH 2017 The role of intracytoplasmic sperm injection in non-male factor infertility in advanced maternal age. Human Reproduction 32 119-124.

Thadani VM 1980 A study of hetero-specific sperm-egg interactions in the rat, mouse, and deer mouse using in vitro fertilization and sperm injection. Journal of Experimental Zoology 212 435-453. (https://doi. org/10.1002/jez.1402120316)

Trounson A 1982 Current perspectives of in vitro fertilization and embryo transfer. Clinical Reproduction and Fertility 1 55-65.

Trounson A \& Wood C 1981 Extracorporeal fertilization and embryo transfer. Clinical Obstetrics and Gynecology 8 681-713.

Trounson A \& Wood C 1984 In vitro fertilization results, 1979-1982, at Monash University, Queen Victoria, and Epworth Medical Centres. Journal of in Vitro Fertilization and Embryo Transfer 1 42-47. (https://doi. org/10.1007/BF01129619)

Trounson AO, Leeton JF, Wood C, Webb J \& Wood J 1981 Pregnancies in humans by fertilization in vitro and embryo transfer in the controlled ovulatory cycle. Science 212 681-682. (https://doi.org/10.1126/ science.7221557)

Uehara T \& Yanagimachi R 1977a Activation of hamster eggs by pricking. Journal of Experimental Zoology 199 269-274. (https://doi.org/10.1002/ jez.1401990211)

Uehara T \& Yanagimachi R 1977b Behavior of nuclei of testicular, caput and cauda epididymal spermatozoa injected into hamster eggs. Biology of Reproduction 16315-321. (https://doi.org/10.1095/biolreprod16.3.315)

Yanagimachi R 2012 Fertilization studies and assisted fertilization in mammals: their development and future. Journal of Reproduction and Development 58 25-32. (https://doi.org/10.1262/jrd.11-015)

Yovich JM, Edirisinghe WR, Cummins JM \& Yovich JL 1990 Influence of pentoxifylline in severe male factor infertility. Fertility and Sterility $\mathbf{5 3}$ 715-722. (https://doi.org/10.1016/S0015-0282(16)53470-0)

Received 9 June 2017

First decision 26 July 2017

Revised manuscript received 19 September 2017

Accepted 9 October 2017 